\title{
O desempenho terminológico dos descritores em Ciência da Informação do Vocabulário Controlado do SIBi/USP nos processos de indexação manual, automática e semi-automática
}

Vania Mara Alves Lima

Professora Doutora do Departamento de Biblioteconomia e Documentação da Escola de Comunicações e Artes da Universidade de São Paulo- DBD/ECA-USP.

Vera Regina Casari Boccato

Professora Assistente do Departamento de Ciência da Informação do Centro de Educação e Ciências Humanas da Universidade Federal de São Carlos - DCI/CECH-UFSCar e Doutoranda do Programa de Pós-graduação em Ciência da Informação da UNESP - Campus de Marília

Avaliou-se o desempenho terminológico, nos processos de indexação manual, automática e semi-automática, dos descritores, do Vocabulário Controlado do SIBi/USP, que representam o domínio da Ciência da Informação. Concluiu-se que os atuais descritores em Ciência da Informação do Vocabulário Controlado do SIBi/USP para representar adequadamente o conteúdo do corpus indexado devem ser ampliados e contextualizados através de definições terminológicas, de maneira a atender as necessidades de informação de seus usuários.

Palavras-chave: Indexação; Indexação automática; Indexação semi-automática; Terminologia; Vocabulário controlado.

\section{Terminological performance of information science descriptors of the SIBI/USP Controlled Vocabulary in manual, automatic and semi-automatic indexing processes}


The terminological performance of the descriptors representing the Information Science domain in the SIBI/USP Controlled Vocabulary was evaluated in manual, automatic and semi-automatic indexing processes. It can be concluded that, in order to have a better performance (i.e., to adequately represent the content of the corpus), current Information Science descriptors of the SIBi/USP Controlled Vocabulary must be extended and put into context by means of terminological definitions so that information needs of users are fulfilled.

Keywords: Indexing; Automatic indexing; semiautomatic indexing; Terminology; Controlled vocabulary

Recebido em 25.08.2008 Aceito em 12.03.2009

\section{Introdução}

As Tecnologias de Informação e Comunicação (TICs) contribuem para o desenvolvimento de processos e instrumentos aplicados ao tratamento da informação documentária.

No âmbito do tratamento temático da informação, a utilização dessas tecnologias possibilita o desenvolvimento de softwares para a construção, manutenção e gerenciamento de linguagens documentárias, bem como a automação da atividade de indexação, visando à otimização dos procedimentos e dos recursos aplicados na representação e recuperação da informação.

Nesse sentido, estudos sobre a temática indexação automática e semi-automática são desenvolvidos com o intuito de agilizar a indexação de fontes de informação, dentro de um cenário em que os usuários se apresentam cada vez mais exigentes na recuperação da informação condizente com suas necessidades de busca.

Associadas a essa realidade, as linguagens documentárias construídas de acordo com os princípios e métodos estabelecidos pela terminologia propiciam a compatibilidade entre a linguagem do usuário e a utilizada pelo sistema de recuperação da informação.

Dessa forma, este estudo tem por objetivo avaliar o desempenho terminológico, nos processos de indexação manual, automática e semiautomática, dos descritores do Vocabulário Controlado do Sistema Integrado de Bibliotecas da Universidade de São Paulo (SIBi/USP), que representam o domínio da Ciência da Informação, constituído nesse instrumento pelas áreas da Biblioteconomia e Documentação, Arquivística e Museologia. 
O Vocabulário Controlado do SIBi/USP é uma linguagem documentária construída, a partir de procedimentos terminológicos e documentários, pelos bibliotecários do SIBi/USP, com a participação de especialistas de todas as áreas do conhecimento abrangidas pelos seus descritores. Essa linguagem documentária permite a representação e a recuperação dos conteúdos documentários presentes nos acervos das 42 bibliotecas que compõem o SIBI/USP.

Essa avaliação compara e analisa os resultados obtidos quando da indexação manual, automática e semi-automática dos resumos das teses e dissertações defendidas no período de janeiro de 2002 a dezembro de 2007 no Programa de Pós-Graduação em Ciência da Informação da Escola de Comunicações e Artes da Universidade de São Paulo (ECA/USP).

$\mathrm{Na}$ indexação automática aplicamos o "Sistema de Indización Automático" (SISA) desenvolvido pelo Professor Isidoro Gil Leiva da Universidade de Múrcia, na Espanha. O SISA seleciona automaticamente os descritores a serem atribuídos a um texto, a partir de sua comparação com o vocabulário controlado de um sistema de informação e com uma lista de palavras consideradas vazias, ou seja, palavras sem significação, como conectivos, artigos, etc. Além disso relaciona em lista à parte os termos candidatos a descritores, isto é, palavras que não estão no vocabulário controlado, mas que apresentam várias ocorrências no texto indexado.

O corpus desse estudo é constituído:

1. dos descritores atribuídos pelos indexadores humanos às dissertações e teses defendidas no PPGCI entre 20022 2007, quando inseridas no Banco de Dados Bibliográficos da USP (DEDALUS);

2. dos descritores atribuídos automaticamente pelo SISA aos resumos dessas dissertações e teses;

3. dos descritores atribuídos semi-automaticamente pelo SISA, ou seja, aqueles descritores selecionados por indexador humano a partir dos descritores atribuídos automaticamente pelo SISA em conjunto com os termos candidatos indicados pelo programa como possíveis descritores.

\section{Procedimentos terminológicos na construção do Vocabulário Controlado do SIBi/USP - VOCAUSP}

De acordo com Lara (2004, p. 232) a linguagem documentária é "[...] uma linguagem especialmente construída para organizar e facilitar o acesso e a transferência da informação". O Vocabulário Controlado do SIBI/USP, como toda linguagem documentária, é um instrumento de organização e recuperação da informação, construído com a finalidade de propiciar a representação e a recuperação dos conteúdos informacionais dos documentos cadastrados no Banco de Dados Bibliográficos da USP 
(DEDALUS), a partir de subsídios teóricos e metodológicos da Análise Documentária e também da Terminologia.

A Terminologia, segundo Dubuc (1999), permite identificar e analisar o vocabulário de uma determinada especialidade e, se necessário, criar e normalizar termos em situações concretas de funcionamento. Assim, a terminologia estuda, teoricamente, os termos e seus respectivos conceitos, os sistemas de conceitos e sua representação.

Tálamo, Lara e Kobashi (1992, p. 1999) afirmam que:

[...] cabe à terminologia, desse modo, operar ao nível sintático-semântico, produzindo terminologias específicas de acordo com o estado-da-arte de cada campo considerado. Tais repertórios ou listas de termos especializados de um domínio particular são acompanhados de definições que remetem 0 termo ao seu referente $[. .$.$] .$

Dentro desse contexto, a Terminologia possui três correntes teóricas básicas que fundamentam esses princípios, a saber (BARROS, 2004):

1. Teoria Geral da terminologia (TGT): tendo uma função conceptual ou cognitiva, é relacionada com a análise e descrição da terminologia, mais especificamente com os estudos, a harmonização e a organização dos domínios, através da sistematização dos termos, e é representada por seu principal teórico Eugen Wüster;

2. Teoria Comunicativa da Terminologia (TCT): apresentada por Maria Tereza Cabré (1993), prioriza a função comunicacional da linguagem, relacionando-se com a comunicação e com a transferência do conhecimento. Essa transferência possibilita a atualização das terminologias através do discurso científico e técnico;

3. Socioterminologia: valoriza os aspectos sociais da linguagem de especialidade e parte do pressuposto de que a "prática terminológica é inseparável tanto do conhecimento do espaço da ação onde ela se dá, quanto das práticas de linguagem que visa modificar ou assegurar" (GAUDIN, 1993, 9. 212) apud BARROS, 2004, p. 69). Nos estudos de François Gaudin (1993), observa-se que essa teoria valoriza a identidade específica de indivíduos, com a finalidade de resgatar línguas em processo de extinção.

\section{Isso posto, e segundo Boccato (2005, p. 53):}

A função da terminologia é a de promover consistência das relações lógico-semânticas na construção de linguagens documentárias, sendo igualmente consideradas as unidades da linguagem natural e das linguagens dos especialistas para a construção de representações adequadas de conceitos por meios de termos. 
A terminologia tem grande importância nos estudos e na elaboração da linguagem documentária; e esta, como um instrumento comunicador de mensagens e mediador da recuperação da informação documentária, tem um papel fundamental no tratamento e na recuperação da informação.

A terminologia, enquanto ciência de estudo dos termos, e mais especificamente a TGT, é um dos referenciais teóricos utilizados para a construção do Vocabulário Controlado do SIBi/USP; ao mesmo tempo em que as terminologias, enquanto conjuntos das entidades lexicais típicas das áreas do conhecimento, abrangidas por essa linguagem documentária, são utilizadas como referentes de seus descritores.

De acordo com a TGT, o objeto de estudo da Terminologia são os conceitos, sendo que os termos ou os símbolos são apenas suas formas designativas. São os conceitos que apresentam relações entre si dentro de um mesmo domínio e podem ser organizados em uma estrutura, formando um conjunto sistematizado (BARROS, 2004).

O estabelecimento das relações entre os conceitos de um domínio norteia a metodologia para a manutenção do Vocabulário Controlado do SIBi/USP, pois, segundo Lima, Boccato et al. (1998, p. 2), essa linguagem documentária pretende uma maior equivalência entre os assuntos adotados em cada biblioteca a partir da aproximação às terminologias das áreas do conhecimento envolvidas.

Esse princípio possibilita ao Vocabulário Controlado do SIBi/USP tornar-se uma linguagem documentária intermediária, constituída de uma estrutura lógico-semântica que atua efetivamente como um instrumento normatizador básico na atividade de indexação do sistema de informação.

A estrutura conceitual de cada domínio no Vocabulário Controlado do SIBi/USP é constituída pelas terminologias das área coletadas, a partir de materiais bibliográficos e instrumentos técnicos/especializados, como tesauros de áreas, sistemas de classificação, dicionários e glossários, entre outros, além da verificação da estrutura curricular de cada unidade de ensino e/ou pesquisa, bem como a realização de consulta aos especialistas de área.

Procurou-se eliminar as redundâncias e termos ambíguos, elaborando-se fichas terminológicas para determinar os termos preferenciais, incluir qualificadores, notas de escopo e operadores de equivalência (VER), realizando a normalização dos termos e garantindo a homogeneidade formal e a univocidade da relação termo-conceito (UNIVERSIDADE DE SÃO PAULO, 2006).

Um grupo gestor, formado por bibliotecários do SIBi/USP e técnicos do DT/SIBi que contam com a assessoria de professores especialistas em Linguagens Documentárias do Departamento de Biblioteconomia e Documentação da ECA/USP, garante a continuidade do processo, a manutenção e o gerenciamento do Vocabulário Controlado do SIBi/USP. 


\section{A indexação manual, automática e semi-automática}

A indexação é o processo de análise documentária que tem por finalidade identificar o assunto de que trata o documento e representá-lo através de descritores de uma linguagem documentária, de maneira a permitir a sua recuperação pelos usuários de um sistema de informação.

Chaumier (1988, p. 63) define indexação como a "operação que consiste em escrever e caracterizar um documento, com o auxílio da representação dos conceitos nela contidos". Essa operação pode ser realizada por um indexador humano, sendo nesse caso denominada na literatura indexação manual; por um programa de computador, sendo denominada indexação automática; ou ainda por um programa de computador e depois revista por um indexador humano, sendo denominada indexação semi-automática.

$\mathrm{Na}$ indexação manual o indexador, em um primeiro momento, realiza a leitura documentária para a identificação e a seleção dos conceitos expressos em um documento e, a seguir, representa ("traduz") esses conceitos selecionados em descritores da linguagem documentária adotada pelo Sistema de Informação (BOCCATO, 2005).

$\mathrm{Na}$ indexação automática, segundo Santos e Ribeiro (2003), um programa de computador, adotando critérios de freqüência, extrai palavras, expressões ou radicais de palavras do texto para representar o seu conteúdo como um todo.

Lancaster (2004, p. 286-290) define dois tipos diferentes de indexação automática. A indexação por extração automática e a indexação por atribuição automática.

$\mathrm{Na}$ indexação por extração automática, palavras ou expressões que aparecem no texto são extraídas, por um programa de computador, e utilizadas para representar o conteúdo do texto como um todo, adotandose critérios de freqüência, posição e contexto (LANCASTER, 2004, p. 286). O programa vai contar as palavras num texto, desde que ele tenha sido cotejado com uma lista de palavras proibidas, a fim de eliminar palavras não-significativas (artigos, preposições, conjunções, etc.), e em seguida ordenar essas palavras segundo a frequência de sua ocorrência. As palavras com maior número de ocorrências são escolhidas como os descritores do documento.

$\mathrm{Na}$ indexação por atribuição automática é necessário desenvolver, para cada termo a ser atribuído, um "perfil" de palavras ou expressões que costumam ocorrer frequentemente nos documentos às quais um indexador humano atribuiria esse termo. Se a cada termo de um vocabulário controlado correspondesse um perfil desses, seria possível utilizar programas de computador para cotejar as expressões importantes num documento (essencialmente aquelas que fossem extraídas segundo critérios de freqüência) com essa coleção de perfis, atribuindo um termo ao documento sempre que esse perfil do documento coincidisse com 0 perfil dos termos (LANCASTER, 2004, p. 289). 
Lancaster (2004, p. 312) considera que apesar da indexação automática não alcançar o nível de desempenho obtido por indexadores humanos, esse tipo de processo poderá reduzir a carga de trabalho desses indexadores ao realizar uma atribuição preliminar.

Segundo Pinto (2001, p. 227), a indexação semi-automática seria a combinação da indexação manual com a indexação automática. Inicialmente, o sistema realiza uma indexação automática dos documentos levando em conta as ocorrências das palavras mais freqüentes no texto. Em um segundo momento, o indexador humano refina a lista dos descritores propostos pelo sistema fazendo os ajustes e/ou complementações necessárias.

\section{Metodologia}

Para a avaliação do desempenho terminológico dos descritores em Ciência da Informação do Vocabulário Controlado do SIBi/USP nos processos de indexação manual, automática e semi-automática, utilizamos como corpus 70 resumos das dissertações e teses, defendidas no Programa de Pós-Graduação em Ciência da Informação da Escola de Comunicações e Artes da Universidade de São Paulo, cadastradas no Banco de Dados Bibliográficos da USP (DEDALUS), no período de janeiro de 2002 a dezembro de 2007. A delimitação do período deve-se ao fato de que a implantação do Vocabulário Controlado do SIBi/USP - VOCAUSP ocorreu em outubro de 2001.

Utilizamos para indexação automática e semi-automática o software "Sistema de Indización Automático" (SISA), desenvolvido pelo professor Isidoro Gil Leiva da Universidade Múrcia na Espanha (GIL LEIVA, 1999). A escolha desse software se deu pela interface facilitadora de seu sistema; por permitir a comparação entre os termos presentes em um resumo e no texto completo de um artigo, com uma lista de descritores previamente escolhidos; e por eliminar, também a partir de uma lista pré-estabelecida, as palavras consideradas "vazias", isto é, palavras sem significação como conectivos, artigos, etc, além de relacionar como termos candidatos palavras que não estão relacionadas como descritores, mas que apresentam várias ocorrências no título e no resumo.

Originalmente o SISA traz como default uma lista de descritores, em espanhol, compilados a partir dos seguintes tesauros em espanhol: "Tesauro em documentacíon e informacíon", Tesauro de la UNESCO e "Vocabulário controlado em bibliotecologia, ciência de la informacíon y temas afins" (GIL LEIVA, 1999, p.106). Assim como também uma lista de palavras vazias. Por esse motivo, o primeiro passo foi o de preparar e inserir no SISA essas respectivas listas em português, a partir dos descritores e termos genéricos da Ciência da Informação retirados do Vocabulário Controlado do SIBI/USP, e ao mesmo tempo traduzir lista de palavras vazias do espanhol, inserindo pequenas alterações.

O SISA exige que todos os textos a serem indexados estejam no formato txt e marcados com os seguintes parâmetros (SISA, s.d.): 
- \#CTI\# e \#FTI\# para identificar o título;

- \#CR\# e \#FR\# para identificar o resumo;

- \#CTE\# e \#FTE\# para identificar o texto do artigo.

Assim, capturamos cada resumo do DEDALUS, salvando-o no formato txt e inserindo em cada um as citadas marcas.

Nesse estudo, por termos acesso apenas aos resumos das dissertações e teses, o resumo foi repetido entre os parâmetros para o texto completo, pois o SISA só realiza a indexação quando existe um corpus entre todos os parâmetros.

Após a preparação das listas e do corpus, realizamos a indexação automática e salvamos em um arquivo os descritores atribuídos pelo software a cada um dos resumos.

Posteriormente, realizamos a indexação semi-automática. Isto é, a partir da leitura do resumo, avaliamos os descritores atribuídos automaticamente a cada um pelo SISA, assim como os termos candidatos à indexação indicados pelo software, optando por aqueles que, de acordo com o nosso entendimento do resumo, representavam mais adequadamente o seu conteúdo informacional. Os resultados são apresentados a seguir.

\section{Resultados}

A partir dos dados obtidos foi possível elaborar um quadro comparativo (Anexo 1) onde para cada resumo indicamos: os descritores atribuídos na indexação manual realizada durante o cadastramento no DEDALUS; os descritores atribuídos automaticamente pelo SISA; e os descritores atribuídos por nós, os quais configuram uma indexação semiautomática .

Esse quadro nos permitiu visualizar graficamente, conforme os QUADROS 1,2 e 3 e os GRÁF. 1, 2 e 3, a coincidência entre os diferentes processos de indexação, e avaliar o desempenho terminológico dos descritores.

No QUADRO 1 observa-se que a grande maioria dos resumos, 67\%, não obteve nenhum descritor coincidente entre a indexação manual e a indexação automática; $27 \%$ dos resumos apresentaram apenas 1 descritor coincidente nos dois processos de indexação e $6 \%$ dos resumos apresentaram 2 descritores coincidentes nos dois processos de indexação. 
QUADRO 1 -Indexação Manual x Indexação Automática

\begin{tabular}{|l|c|c|}
\hline $\begin{array}{l}\text { Indexação Manual x Indexação Automática: } \\
\text { coincidência de descritores }\end{array}$ & $\begin{array}{c}\text { Número de } \\
\text { Resumos }\end{array}$ & $\mathbf{\%}$ \\
\hline 2 descritores & 4 & 6 \\
\hline 1 descritor & 19 & 27 \\
\hline 0 descritor & 47 & 67 \\
\hline Total de resumos & $\mathbf{7 0}$ & $\mathbf{1 0 0}$ \\
\hline
\end{tabular}

Fonte: dados da pesquisa.

A coincidência dos descritores pode ser observada no GRÁF. 1.

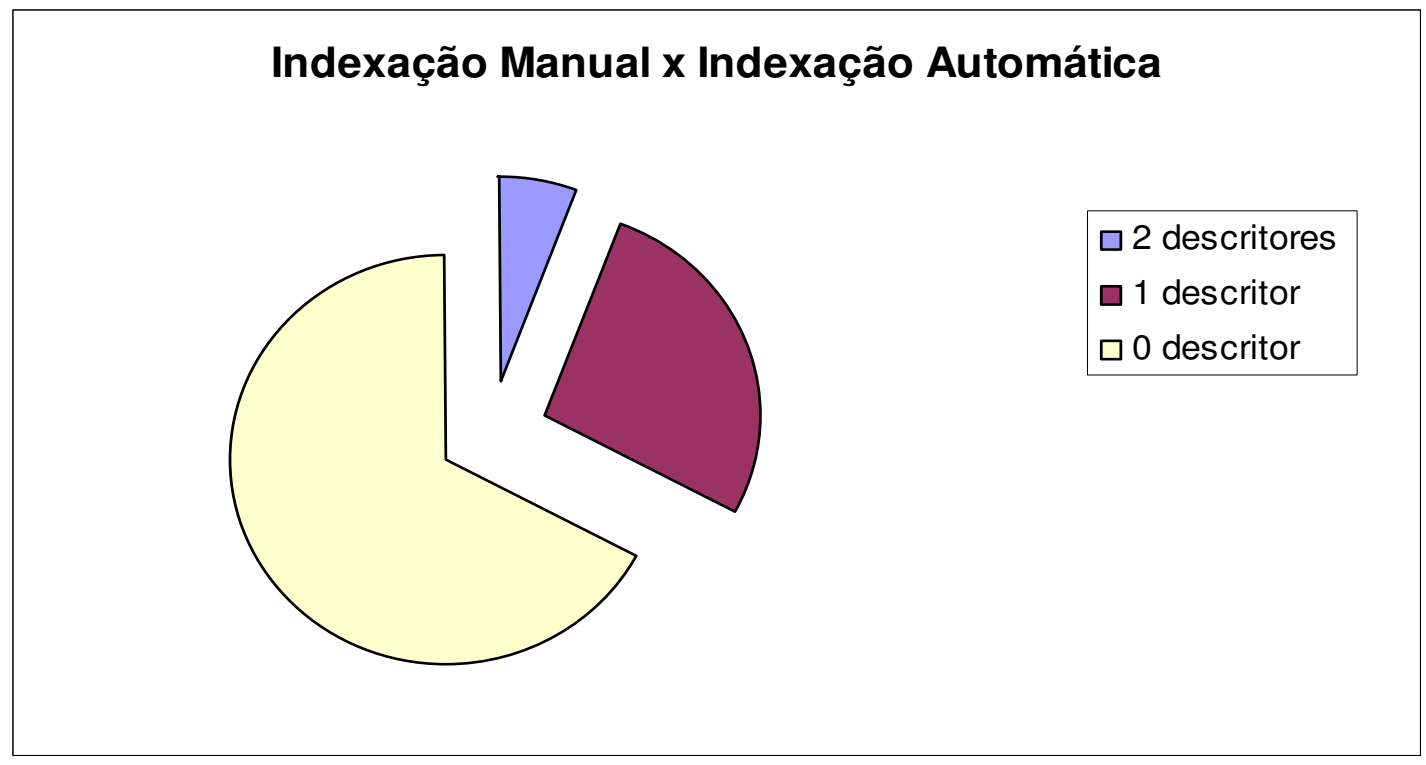

GRÁFICO 1 - Indexação Manual x Indexação Automática

Fonte: dados da pesquisa.

O QUADRO 2 apresenta os resultados de descritores coincidentes nos processos de indexação manual e de indexação semi-automática, onde $51 \%$ dos resumos apresentaram coincidência de 1 descritor; $29 \%$ não apresentaram nenhum descritor coincidente, $16 \%$ dos resumos coincidem em 2 descritores e $4 \%$ coincidem em 3 descritores. 
QUADRO 2 - Indexação Manual x Indexação Semi-Automática: coincidência de descritores

\begin{tabular}{|l|c|c|}
\hline $\begin{array}{l}\text { Indexação Manual x Indexação Semi-Automática: } \\
\text { coincidência de descritores }\end{array}$ & $\begin{array}{l}\text { Número de } \\
\text { Resumos }\end{array}$ & $\mathbf{\%}$ \\
\hline 3 descritores & 3 & 4 \\
\hline 2 descritores & 11 & 16 \\
\hline 1 descritor & 36 & 51 \\
\hline 0 descritor & 20 & 29 \\
\hline Total de resumos & $\mathbf{7 0}$ & $\mathbf{1 0 0}$, \\
\hline
\end{tabular}

Fonte: dados da pesquisa.

No GRÁF. 2 podemos visualizar os resultados apresentados no QUADRO 2.

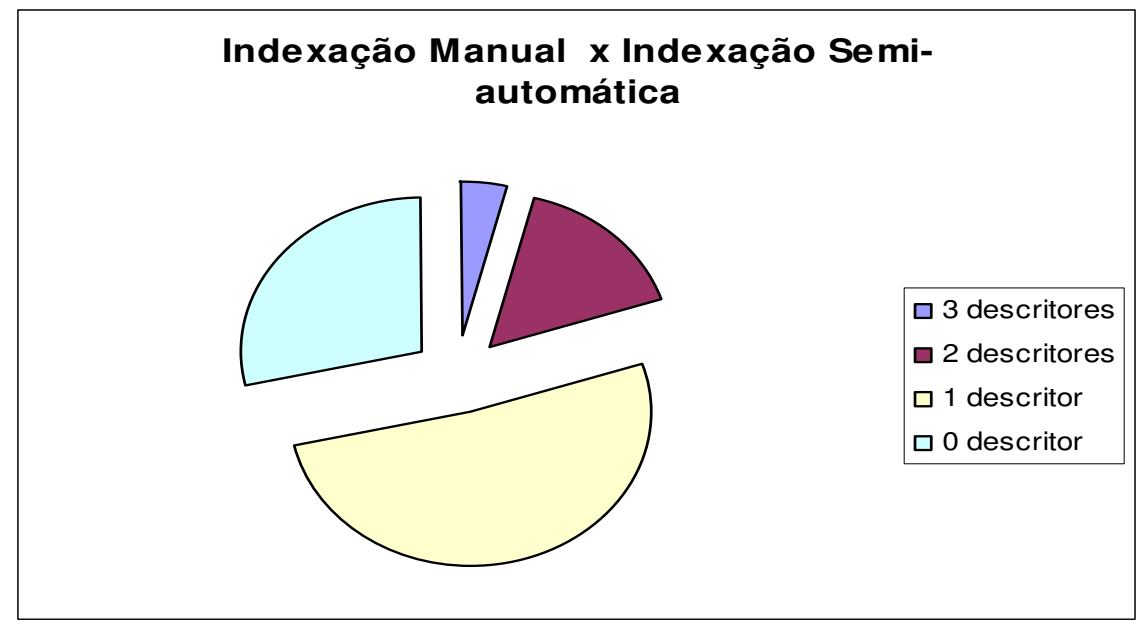

GRÁFICO 2 - Indexação Manual x Indexação Semi-Automática

Fonte: dados da pesquisa.

No QUADRO 3 observamos a coincidência de descritores entre a indexação automática e a indexação semi-automática, onde $51 \%$ dos resumos não apresentam descritores coincidentes nos dois processos, $38 \%$ apresentam apenas um descritor coincidente, $10 \%$ dos resumos apresentam 2 descritores coincidentes, $1 \%$ apresenta 3 descritores coincidentes e $1 \%$ apresenta 5 descritores coincidentes. 
QUADRO 3 - Indexação Automática x Indexação Semi-Automática: coincidência de descritores

\begin{tabular}{|l|c|c|}
\hline $\begin{array}{l}\text { Indexação Automática x Indexação } \\
\text { Semi-Automática: coincidência de } \\
\text { descritores }\end{array}$ & Número de Resumos & \% \\
\hline 5 descritores & 1 & 1 \\
\hline 3 descritores & 1 & 1 \\
\hline 2 descritores & 7 & 10 \\
\hline 1 descritor & 26 & 38 \\
\hline 0 descritor & 35 & 51 \\
\hline Total de resumos & $\mathbf{7 0}$ & $\mathbf{1 0 0}$ \\
\hline
\end{tabular}

Fonte: dados da pesquisa.

No GRÁF. 3 visualizamos os resultados apresentados no QUADRO 3.

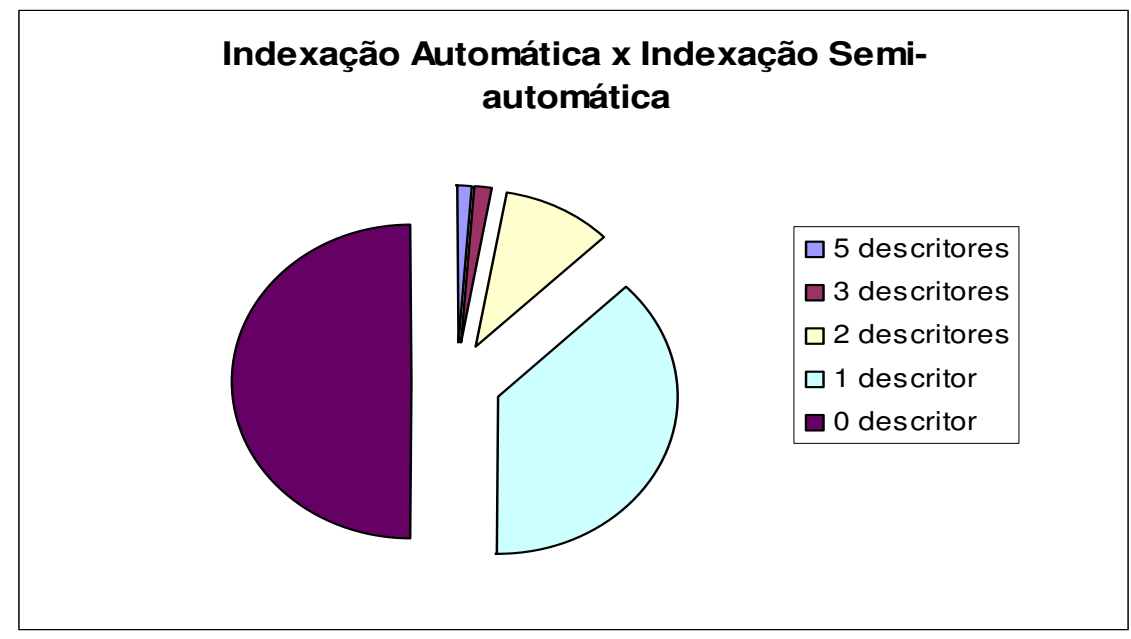

GRÁFICO 3 - Indexação Automática x Indexação SemiAutomática

Fonte: dados da pesquisa.

A partir desses resultados, e analisando os descritores selecionados nos 3 processos de indexação apresentados no ANEXO I, relacionamos algumas considerações, não apenas sobre os processos de indexação realizados, como também sobre o objeto do processo de indexação, ou seja, os resumos, e ainda sobre a ferramenta utilizada no processo, o SISA. Os resultados indicam também as áreas que são objeto do maior número de dissertações e teses nas linhas de pesquisa do Programa de Pós-graduação de Ciência da Informação da ECA/USP.

Em alguns casos infere-se que os resumos não foram elaborados adequadamente, pois, na indexação semi-automática o indexador identificou o assunto tratado na dissertação ou tese e esse assunto fazia parte do Vocabulário, mas não foi indexado pelo SISA por não ter sido nomeado no resumo, como no exemplo, a seguir. 


\begin{tabular}{|l|l|l|}
\hline Autor & Título & Assunto \\
\hline $\begin{array}{l}\text { Aguiar, Maria } \\
\text { Lucinda } \\
\text { Meirelles }\end{array}$ & $\begin{array}{l}\text { Organização e disponibilização de bases de } \\
\text { informações municipais para gestão de políticas } \\
\text { públicas }\end{array}$ & Gestão da informação \\
\hline
\end{tabular}

Observa-se que novos termos, que aparecem nos resumos como novos assuntos do domínio, não foram ainda incorporados pelo Vocabulário como descritores na área da Ciência da Informação, como por exemplo:

INFORMAÇÃO DOCUMENTÁRIA
PRINCÍPIO MONOGRÁFICO
LINGUIISTICA DOCUMENTÁRIA
ALFABETIZAÇÃO DIGITAL
COMUNIDADES VIRTUAIS

O termo Ação Cultural não foi indexado, por não estar incluído no VOCAUSP no domínio da Ciência da Informação, mas sim no domínio das Ciências Sociais, como podemos observar no esquema a seguir:

\section{CH764.5 - SOCIOLOGIA \\ CH764.5.2 - CULTURA \\ CH764.5.2.9 - POLÍTICA CULTURAL \\ CH764.5.2.9.7 - AÇÃO CULTURAL}

Verifica-se também que o software não reconhece os descritores compostos, como, por exemplo, Ciência da Informação, quando no texto surge também o termo Informação. Isso ocorre porque Informação também é um descritor do Vocabulário e acaba sendo contado isoladamente. Consequentemente obtém um maior número de ocorrências.

\section{Considerações finais}

Durante o processo de avaliação do desempenho terminológico dos descritores em Ciência da Informação do Vocabulário Controlado do SIBi/USP, identificamos alguns ruídos na recuperação da informação realizada devido a problemas não só dos resumos inseridos no sistema de informação, DEDALUS, como também da linguagem documentária utilizada nesse sistema para indexação de seus registros, e ainda das limitações da ferramenta utilizada na indexação automática e semiautomática.

Consideramos que em alguns casos os resumos não são elaborados adequadamente, não permitindo uma indexação automática e dificultando 
também uma indexação semi-automática; isso porque na maioria das vezes são elaborados pelos autores e não por profissionais da área da CI, e não utilizam em seu corpus a terminologia do domínio no qual estão inseridos. Isso pôde ser observado no processo de indexação semiautomática, quando o indexador identificou o assunto tratado na dissertação ou tese e esse assunto fazia parte do Vocabulário, mas não foi indexado pelo SISA, por não ter sido nomeado no resumo. No caso de resumos elaborados adequadamente, a indexação automática representou satisfatoriamente o conteúdo informacional do documento, mas conclui-se pela necessidade de um tratamento anterior dos registros a serem cadastrados em uma base de dados.

Com relação à linguagem documentária, apesar de ter sido construída a partir de procedimentos terminológicos, ela ainda necessita ser aprimorada, no sentido de dar uma maior consistência terminológica aos seus descritores. Isso pode se observado pela inexistência, no Vocabulário Controlado do SIBi/USP, de novos termos, que aparecem nos resumos como novos assuntos do domínio e não foram ainda incorporados pelo Vocabulário como descritores na área da Ciência da Informação. Outro problema identificado foi que a linha de pesquisa Ação Cultural não se encontra adequadamente representada no Vocabulário no domínio da Ciência da Informação e sim no domínio da Sociologia. Isso demonstra a necessidade de inserção de áreas interdisciplinares, o que levaria a uma proposta de inserção de todo o Vocabulário Controlado do SIBi/USP no SISA.

Com relação ao SISA, ao processar apenas arquivos em txt o programa fica limitado ao que se encontra disponível nesse formato, o que também leva à necessidade de preparo do corpus a ser indexado. 0 aprimoramento do programa para indexar textos em outros formatos, mais especificamente o pdf, seria de grande valia para os sistemas de informação, visto que a maioria dos repositórios de textos completos se encontra nesse formato.

Consideramos que a utilização do SISA na indexação semiautomática é a mais adequada, pois permite ao indexador avaliar novos termos que surgem como termos candidatos à indexação e que representam em muitos casos novas fronteiras do conhecimento que vem sendo desenvolvido na área, estando presentes nas terminologias das áreas de domínio

Dessa maneira, a indexação semi-automática permite atualizar os instrumentos de indexação de um Sistema de Informação, já que indica, através dos termos candidatos, a atualização terminológica de uma determinada área do conhecimento.

O desempenho terminológico dos termos depende da atualização terminológica da linguagem documentária a ser utilizada nos processos de indexação. A partir dos resultados obtidos podemos considerar que os atuais descritores em Ciência da Informação do Vocabulário Controlado do SIBi/USP, para obterem um melhor desempenho, ou seja, representarem adequadamente o conteúdo do corpus indexado, devem ser ampliados e 
ainda contextualizados através de definições terminológicas, para que possam responder efetivamente às necessidades de informação de seus usuários.

A resposta para a representação adequada dos conteúdos informacionais presentes nas bases de dados parece estar na reunião dos esforços de três áreas: a Terminologia, a Análise documentária e a Informática.

\section{Referências}

BARROS, L. A. Curso básico de terminologia. São Paulo: Edusp, 2004. $185 p$.

BOCCATO, V. R. C. Avaliação de linguagem documentária em Fonoaudiologia na perspectiva do usuário: estudo de observação da recuperação da informação com protocolo verbal. 2005. 239 f. Dissertação (Mestrado em Ciência da Informação) - Faculdade de Filosofia e Ciências, Universidade Estadual Paulista, Marília, 2005.

BOCCATO, V. R. C. Avaliação de linguagem documentária em Fonoaudiologia na perspectiva do usuário: estudo de observação da recuperação da informação com protocolo verbal. 2005. 239 f. Dissertação (Mestrado em Ciência da Informação) - Faculdade de Filosofia e Ciências, Universidade Estadual Paulista, Marília, 2005.

CABRÉ, M. T. La terminología: teoria, metodología, aplicaciones. Barcelona: Antártica/Empúres, 1993. 529 p.

CHAUMIER, J. Indexação: conceito, etapas e instrumentos. Revista Brasileira de Biblioteconomia e Documentação, São Paulo, v. 21, n. 1/2, p. 63-79, jan./jun. 1988.

DUBUC, R. ¿Qué es la terminología?: Manual de terminología. Providencia: Ril Ed., 1999.

GAUDIN, F. Socioterminologie: dês problèmes sémantiques aux pratiques institutionnelles. Rouen: Université de Rouen, 1993 apud BARROS, L. A. Curso básico de terminologia. São Paulo: Edusp, 2004. 185 p.

GIL LEIVA, I. La automatizacíon de la indización de documentos. Gijón (Asturias): Ediciones Trea, 1999.

LANCASTER, F. W. Indexação e resumos: teoria e prática. 2. ed. Brasília: Briquet de Lemos, 2004. 452 p.

LARA, M. L. Linguagem documentária e terminologia. Transinformação, Campinas, v. 16, n. 3, p. 231-240, set./dez. 2004.

LIMA, V. M. A. ; BOCCATO, V. R. C. et al. Atualização da lista de assuntos USP: compatibilização de linguagens documentárias. Ciência da Informação, São Paulo, v. 25, n. 2, p. 177-181, mai/ago. 1996. 
PINTO, V. B. Indexação documentária: uma forma de representação do conhecimento registrado. Perspectivas em Ciência da Informação, Belo Horizonte, v. 6, n. 2, p. 223 - 234, jul./dez. 2001.

SANTOS, G. C.; RIBEIRO, C. M. Acrônimos, siglas e termos técnicos: Arquivística, Biblioteconomia, Documentação, Informática. Campinas: Átomo, 2003. 277 p.

SISA: Sistema de Indizacíon Semi-Automático: guia de usuário. Múrcial: [s.n.] 1998. 16p.

TÁLAMO, M. F. G. M.; LARA, M. L. G.; KOBASHI, N. Y. Contribuição da terminologia para a elaboração de tesauros. Ciência da Informação, Brasília, v. 21, n. 3, p. 197-200, set./dez. 1992.

UNIVERSIDADE DE SÃO PAULO. Vocabulário Controlado do SIBi/USP. Disponível em: <http://www.usp.br/sibi> . Acesso em: 11 mar. 2008. 


\section{ANEXO 1 - Quadro dos descritores atribuídos aos resumos}

\begin{tabular}{|c|c|c|c|c|}
\hline AUTOR & TÍTULO & $\begin{array}{c}\text { INDEXAÇÃO MANUAL } \\
\text { NO DEDALUS }\end{array}$ & $\begin{array}{c}\text { INDEXAÇÃO } \\
\text { AUTOMÁTICA } \\
\text { (SISA) }\end{array}$ & $\begin{array}{c}\text { INDEXAÇÃO } \\
\text { SEMI- } \\
\text { AUTOMÁTICA }\end{array}$ \\
\hline $\begin{array}{l}\text { Abdala, } \\
\text { C.V.M. }\end{array}$ & $\begin{array}{l}\text { Critérios de qualidade do } \\
\text { serviço de fornecimento } \\
\text { de documentos científicos } \\
\text { sob a percepção do } \\
\text { usuário final }\end{array}$ & $\begin{array}{l}\text { CIÊNCIA DA INFORMAÇÃO; } \\
\text { COMUTAÇÃO BIBLIOGRÁFICA; } \\
\text { SERVIÇOS DE INFORMAÇÂO } \\
\text { (QUALIDADE); DOCUMENTOS } \\
\text { (FORNECIMENTO) }\end{array}$ & $\begin{array}{l}\text { DOCUMENTOS; } \\
\text { ESTUDO DE CASO; }\end{array}$ & $\begin{array}{l}\text { DOCUMENTOS; } \\
\text { QUALIDADE; } \\
\text { USUÁRIO; }\end{array}$ \\
\hline $\begin{array}{l}\text { Abdalla, E. } \\
\text { R. F. }\end{array}$ & $\begin{array}{l}\text { A seleção da metodologia } \\
\text { da pesquisa por } \\
\text { mestrandos em } \\
\text { biblioteconomia e ciência } \\
\text { da informação }\end{array}$ & $\begin{array}{l}\text { BIBLIOTECONOMIA; CIÊNCIA } \\
\text { DA INFORMAÇÃO; } \\
\text { METODOLOGIA DA PESQUISA }\end{array}$ & $\begin{array}{l}\text { BIBLIOTECONOMIA; } \\
\text { METODOLOGIA DA } \\
\text { PESQUISA; } \\
\text { PESQUISA; }\end{array}$ & $\begin{array}{l}\text { BIBLIOTECONOMIA; } \\
\text { METODOLOGIA DA } \\
\text { PESQUISA; CIÊNCIA } \\
\text { DA INFORMAÇÃO; }\end{array}$ \\
\hline $\begin{array}{l}\text { Aguiar, M.L. } \\
\text { M. }\end{array}$ & $\begin{array}{l}\text { Organização e } \\
\text { disponibilização de bases } \\
\text { de informações } \\
\text { municipais para gestão } \\
\text { de políticas públicas }\end{array}$ & $\begin{array}{l}\text { SERVIÇOS DE INFORMAÇÃO; } \\
\text { LINGUAGENS } \\
\text { DOCUMENTÁRIAS; BASES DE } \\
\text { DADOS; POLÍTICAS PÚBLICAS } \\
\text { - SÃO PAULO (SP); } \\
\text { ADMINISTRAÇÃO MUNICIPAL - } \\
\text { SÃO PAULO (SP); } \\
\text { RECUPERAĈ̃O DA } \\
\text { INFORMAÇÃO. }\end{array}$ & PESQUISA; & $\begin{array}{l}\text { GESTÃO DA } \\
\text { INFORMAÇÃO }\end{array}$ \\
\hline $\begin{array}{l}\text { Amorim, } \\
\text { A.D. G. }\end{array}$ & $\begin{array}{l}\text { A mediação da } \\
\text { informação contábil sob a } \\
\text { ótica da ciência da } \\
\text { informação }\end{array}$ & $\begin{array}{l}\text { CIÊNCIA DA INFORMAÇÃO; } \\
\text { DIFUSÃO DA INFORMAÇÃO; } \\
\text { SISTEMAS DE INFORMAÇÃO } \\
\text { CONTÁBIL; INVESTIMENTOS }\end{array}$ & $\begin{array}{l}\text { PESQUISA; } \\
\text { RELATÓRIOS }\end{array}$ & $\begin{array}{l}\text { SERVIÇOS DE } \\
\text { INFORMAÇÃO; } \\
\text { CIÊNCIA DA } \\
\text { INFORMAÇÃO; TEORIA } \\
\text { DA CONTABILIDADE }\end{array}$ \\
\hline $\begin{array}{l}\text { Amorim, } \\
\text { A.M. }\end{array}$ & $\begin{array}{l}\text { A globalização do } \\
\text { mercado de periódicos } \\
\text { científicos eletrônicos e } \\
\text { os consórcios de } \\
\text { bibliotecas universitárias } \\
\text { brasileiras ... }\end{array}$ & $\begin{array}{l}\text { GLOBALIZAÇÃO; PERIÓDICOS } \\
\text { CIENTÍFICOS; BIBLIOTECA } \\
\text { UNIVERSITÁRIA }\end{array}$ & $\begin{array}{l}\text { BIBLIOTECAS; } \\
\text { PERIÓDICOS; } \\
\text { PERIÓDICOS } \\
\text { CIENTÍFICOS; } \\
\text { BIBLIOTECAS } \\
\text { PÚBLICAS; } \\
\text { DOCUMENTOS; } \\
\text { ESTUDO DE CASO; } \\
\text { PESQUISA; }\end{array}$ & $\begin{array}{l}\text { PERIÓDICOS } \\
\text { CIENTÍFICOS; } \\
\text { DESENVOLVIMENTO } \\
\text { DE COLEÇÕES; } \\
\text { CONSÓRCIO DE } \\
\text { BIBLIOTECAS; }\end{array}$ \\
\hline Andraus, G. & $\begin{array}{l}\text { As histórias em } \\
\text { quadrinhos como } \\
\text { informação imagética } \\
\text { integrada ao ensino } \\
\text { universitário }\end{array}$ & $\begin{array}{l}\text { HISTÓRIA EM QUADRINHOS; } \\
\text { EDUCAÇÃO; INFORMAÇÃO; } \\
\text { ENSINO SUPERIOR }\end{array}$ & $\begin{array}{l}\text { ANÁLISE DE } \\
\text { CONTEÚDO; ESTUDO } \\
\text { DE CASO; LIVROS; } \\
\text { PESQUISA; }\end{array}$ & $\begin{array}{l}\text { ANÁLISE DE } \\
\text { CONTEÚDO; } \\
\text { REVISTAS EM } \\
\text { QUADRINHOS; } \\
\text { HISTÓRIAS EM } \\
\text { QUADRINHOS; } \\
\text { ENSINO; } \\
\end{array}$ \\
\hline $\begin{array}{l}\text { Artêncio, } \\
\text { L.M. }\end{array}$ & $\begin{array}{l}\text { Princípios de } \\
\text { categorização nas } \\
\text { linguagens documentais }\end{array}$ & $\begin{array}{l}\text { LINGUAGENS } \\
\text { DOCUMENTÁRIAS; } \\
\text { CLASSIFICAÇÃOO }\end{array}$ & $\begin{array}{l}\text { BIBLIOTECONOMIA; } \\
\text { LINGUAGENS } \\
\text { DOCUMENTARIAS; }\end{array}$ & $\begin{array}{l}\text { BIBLIOTECONOMIA; } \\
\text { LINGUAGENS } \\
\text { DOCUMENTARIAS; } \\
\text { CATEGORIZAÇÃO; }\end{array}$ \\
\hline Balby, C. N. & $\begin{array}{l}\text { Estudos de uso de } \\
\text { catálogos on-line } \\
\text { (OPACs) }\end{array}$ & $\begin{array}{l}\text { SISTEMAS DE INFORMAÇÃO; } \\
\text { BIBLIOTECA UNIVERSITARIA - } \\
\text { BRASIL; RECUPERAÇÃO DA } \\
\text { INFORMAÇÃO }\end{array}$ & $\begin{array}{l}\text { CATÁLOGOS; } \\
\text { CATÁLOGOS ON- } \\
\text { LINE; BIBLIOTECAS; } \\
\text { PESQUISA; }\end{array}$ & $\begin{array}{l}\text { CATÁLOGOS ON-LINE; } \\
\text { BIBLIOTECA } \\
\text { UNIVERSITÁRIA; } \\
\text { OPAC; SISTEMAS DE } \\
\text { RECUPERAČ̃̃ DA } \\
\text { INFORMAÇÃO; }\end{array}$ \\
\hline Barizon, A. & \begin{tabular}{|l|} 
Personaliz@ção de \\
sistemas computacionais
\end{tabular} & $\begin{array}{l}\text { CIÊNCIA DA COMPUTAÇÃO; } \\
\text { COMPUTADORES }\end{array}$ & & $\begin{array}{l}\text { SISTEMAS } \\
\text { COMPUTACIONAIS }\end{array}$ \\
\hline $\begin{array}{l}\text { Barreto, } \\
\text { A.M. }\end{array}$ & $\begin{array}{l}\text { Memória de leituras: } \\
\text { trajetória de leitores } \\
\text { idosos do Vale do Paraíba } \\
\text { - uma contribuição ao } \\
\text { Estudo das Relações } \\
\text { entre Informação e } \\
\text { Produção de Sentidos }\end{array}$ & $\begin{array}{l}\text { LEITURA; IDOSOS - VALE DO } \\
\text { PARAIIBA }\end{array}$ & PESQUISA; & $\begin{array}{l}\text { IDOSOS; POLÍTICAS } \\
\text { DE LEITURA; }\end{array}$ \\
\hline
\end{tabular}



automática

\begin{tabular}{|c|c|c|c|c|}
\hline AUTOR & TÍTULO & $\begin{array}{c}\text { INDEXAÇÃO MANUAL } \\
\text { NO DEDALUS }\end{array}$ & $\begin{array}{c}\text { INDEXAÇÃO } \\
\text { AUTOMÁTICA } \\
\text { (SISA) }\end{array}$ & $\begin{array}{c}\text { INDEXAÇÃO } \\
\text { SEMI- } \\
\text { AUTOMÁTICA }\end{array}$ \\
\hline $\begin{array}{l}\text { Bazi, R. E. } \\
\text { R.s }\end{array}$ & $\begin{array}{l}\text { Noticiário regional e a } \\
\text { noção de território: a } \\
\text { construção de processos } \\
\text { identitários }\end{array}$ & $\begin{array}{l}\text { TELEJORNALISMO - BRASIL; } \\
\text { NOTÍCIA }\end{array}$ & PESQUISA; & $\begin{array}{l}\text { PROCESSOS } \\
\text { IDENTITÁRIOS; } \\
\text { IDENTIDADES } \\
\text { CULTURAIS; }\end{array}$ \\
\hline Bliska, A.V. & $\begin{array}{l}\text { Capital social em } \\
\text { comunidades virtuais de } \\
\text { aprendizagem }\end{array}$ & $\begin{array}{l}\text { TECNOLOGIA EDUCACIONAL; } \\
\text { APRENDIZAGEM; } \\
\text { EDUCOMUNICAÇÃO; } \\
\text { COMUNIDADE VIRTUA'; } \\
\text { EDUCAÇÃO A DISTÂNCIA }\end{array}$ & PESQUISA; & $\begin{array}{l}\text { COMUNIDADES } \\
\text { VIRTUAIS; } \\
\text { APRENDIZAGEM; } \\
\text { ALFABETIZAÇÃO } \\
\text { DIGITAL; }\end{array}$ \\
\hline $\begin{array}{l}\text { Boudler, } \\
\text { L.C.V. }\end{array}$ & $\begin{array}{l}\text { A leitura cientifica no } \\
\text { contexto da ciência da } \\
\text { informação }\end{array}$ & $\begin{array}{l}\text { CIÊNCIA DA INFORMAÇÃO; } \\
\text { INFORMAÇÃO; } \\
\text { PESQUISADORES; } \\
\text { COMUNICAÇÃO }\end{array}$ & PESQUISA; & $\begin{array}{l}\text { ESTRATÉGIAS DE } \\
\text { LEITURA; } \\
\text { INFORMAÇÃO } \\
\text { CIENTÍFICA; LEITURA } \\
\text { CIENTÍFICA; }\end{array}$ \\
\hline Braga, G.B. & Conservação preventiva & $\begin{array}{l}\text { CONSERVAÇÃO } \\
\text { MUSEOLÓGICA; ACERVO } \\
\text { (RESTAURAÇÃO); } \\
\text { DOCUMENTOS } \\
\text { (RESTAURAÇÃO; } \\
\text { CONSERVAÇÃO) }\end{array}$ & PESQUISA; & $\begin{array}{l}\text { CONSERVAÇÃO } \\
\text { PREVENTIVA; } \\
\text { ACERVO; } \\
\text { ACONDICIONAMENTO; } \\
\text { ARMAZENAMENTO; } \\
\text { RESERVA TÉCNICA; }\end{array}$ \\
\hline $\begin{array}{l}\text { Caldeira, } \\
\text { C.C. }\end{array}$ & $\begin{array}{l}\text { Conservação preventiva } \\
\text { em bibliotecas públicas } \\
\text { na cidade de São Paulo: } \\
\text { estudo de campo }\end{array}$ & $\begin{array}{l}\text { BIBLIOTECAS } \\
\text { (CONSERVAÇÃO); } \\
\text { BIBLIOTECAS PÚBLICAS - SÃO } \\
\text { PAULO (SP) }\end{array}$ & $\begin{array}{l}\text { BIBLIOTECAS; } \\
\text { BIBLIOTECAS } \\
\text { PÚBLICAS; ACERVO; }\end{array}$ & $\begin{array}{l}\text { BIBLIOTECAS } \\
\text { PÚBLICAS; ACERVO; } \\
\text { CONSERVAÇÃO } \\
\text { PREVENTIVA }\end{array}$ \\
\hline $\begin{array}{l}\text { Calderon, } \\
\text { W.R. }\end{array}$ & $\begin{array}{l}\text { Instrumentos de pesquisa } \\
\text { nos arquivos públicos } \\
\text { permanentes }\end{array}$ & $\begin{array}{l}\text { ANÁLISE DOCUMENTÁRIA; } \\
\text { ARQUIVOS PÚBLICOS; } \\
\text { NORMALIZAÇÃO DA } \\
\text { DOCUMENTAÇÃO }\end{array}$ & $\begin{array}{l}\text { ARQUIVOS; } \\
\text { ARQUIVOS } \\
\text { PÚBLICOS; ANÁLISE } \\
\text { DOCUMENTÁRIA; } \\
\text { PESQUISA; } \\
\text { ARQUIVÍSTICA; } \\
\text { DOCUMENTOS; } \\
\text { ÍNDICES; LIVROS }\end{array}$ & $\begin{array}{l}\text { ARQUIVOS PÚBLICOS; } \\
\text { ANÁLISE } \\
\text { DOCUMENTÁRIA; } \\
\text { ARQUIVÍSTICA; } \\
\text { DOCUMENTOS; } \\
\text { ÍNDICES; ARQUIVOS } \\
\text { PERMANENTES }\end{array}$ \\
\hline $\begin{array}{l}\text { Caputo, M. } \\
\text { A.R. }\end{array}$ & $\begin{array}{l}\text { Histórias em quadrinhos: } \\
\text { um potencial de } \\
\text { informação inexplorado }\end{array}$ & $\begin{array}{l}\text { HISTÓRIA EM QUADRINHOS - } \\
\text { SÉCULO 20; DÉCADA de } 50 \text { - } \\
\text { BRASIL; NARRATIVA; } \\
\text { HISTÓRIA DO BRASIL }\end{array}$ & & $\begin{array}{l}\text { HISTÓRIA EM } \\
\text { QUADRINHOS }\end{array}$ \\
\hline $\begin{array}{l}\text { Carvalho, } \\
\text { T. }\end{array}$ & $\begin{array}{l}\text { A produção científica } \\
\text { brasileira em odontologia } \\
\text { e sua visibilidade nacional } \\
\text { e internacional }\end{array}$ & $\begin{array}{l}\text { PESQUISA CIENTÍFICA; } \\
\text { REVISTAS - BRASIL; } \\
\text { ODONTOLOGIA; BIBLIOMETRIA }\end{array}$ & $\begin{array}{l}\text { BASES DE DADOS; } \\
\text { PESQUISA; } \\
\text { RELATÓRIOS }\end{array}$ & $\begin{array}{l}\text { BASES DE DADOS; } \\
\text { PRODUÇÃO } \\
\text { CIENTÍFICA; } \\
\text { ODONTOLOGIA; }\end{array}$ \\
\hline $\begin{array}{l}\text { Castro } \\
\text { Filho, C. M. } \\
\text { de }\end{array}$ & $\begin{array}{l}\text { Biblioteca no ensino e } \\
\text { aprendizagem da língua } \\
\text { inglesa }\end{array}$ & $\begin{array}{l}\text { SERVIÇOS DE INFORMAÇÃO; } \\
\text { LÍNGUA INGLESA (ESTUDO E } \\
\text { ENSINO); AVALIAÇÃO DE } \\
\text { SERVIÇOS; BIBLIOTECA } \\
\text { ESCOLAR }\end{array}$ & $\begin{array}{l}\text { ACERVO; } \\
\text { BIBLIOTECAS; } \\
\text { BIBLIOTECA } \\
\text { ESCOLAR; COLETA } \\
\text { DE DADOS; } \\
\text { PESQUISA }\end{array}$ & $\begin{array}{l}\text { BIBLIOTECA } \\
\text { ESCOLAR; } \\
\text { APRENDIZAGEM; } \\
\text { ENSINO }\end{array}$ \\
\hline $\begin{array}{l}\text { Castro, E. } \\
\text { de }\end{array}$ & $\begin{array}{l}\text { Informação para apoio à } \\
\text { tomada de decisão em } \\
\text { saúde: parâmetros de } \\
\text { produção de informação } \\
\text { territorializada }\end{array}$ & $\begin{array}{l}\text { INFORMAÇÃO; SAÚDE } \\
\text { PÚBLICA; CIÊNCIA DA } \\
\text { INFORMAÇÃO }\end{array}$ & & $\begin{array}{l}\text { INFORMAÇÃO; SAÚDE } \\
\text { PÚBLICA }\end{array}$ \\
\hline $\begin{array}{l}\text { Castro, E. } \\
\text { de }\end{array}$ & $\begin{array}{l}\text { Informação em saúde } \\
\text { para o público leigo: os } \\
\text { âmbitos da produção e } \\
\text { transferência de } \\
\text { informação nas entidades } \\
\text { de apoio a pacientes } \\
\end{array}$ & $\begin{array}{l}\text { SERVIÇOS DE INFORMAÇÃO; } \\
\text { SISTEMAS DE INFORMAÇÃO; } \\
\text { SAÚDE PÚBLICA - BRASIL; } \\
\text { GRUPOS DE AUTO-AJUDA }\end{array}$ & & $\begin{array}{l}\text { INFORMAÇÃO; } \\
\text { ANÁLISE DO } \\
\text { DISCURSO; }\end{array}$ \\
\hline $\begin{array}{l}\text { Ceravolo, } \\
\text { S.M. }\end{array}$ & $\begin{array}{l}\text { Da palavra ao termo: um } \\
\text { caminho para } \\
\text { compreender a } \\
\text { museologia }\end{array}$ & $\begin{array}{l}\text { MUSEOLOGIA } \\
\text { (TERMINOLOGIA); LINGUAGEM }\end{array}$ & $\begin{array}{l}\text { MUSEOLOGIA; } \\
\text { DOCUMENTOS }\end{array}$ & $\begin{array}{l}\text { MUSEOLOGIA; } \\
\text { LINGUAGEM DE } \\
\text { ESPECIALIDADE }\end{array}$ \\
\hline
\end{tabular}



automática

\begin{tabular}{|c|c|c|c|c|}
\hline AUTOR & TÍTULO & $\begin{array}{c}\text { INDEXAÇÃO MANUAL } \\
\text { NO DEDALUS }\end{array}$ & $\begin{array}{l}\text { INDEXAÇÃO } \\
\text { AUTOMÁTICA } \\
\text { (SISA) }\end{array}$ & $\begin{array}{c}\text { INDEXAÇÃO } \\
\text { SEMI- } \\
\text { AUTOMÁTICA }\end{array}$ \\
\hline Conti, V. L. & $\begin{array}{l}\text { Informação, } \\
\text { conhecimento e a } \\
\text { (re)construção do cosmos } \\
\text { contemporâneo }\end{array}$ & $\begin{array}{l}\text { INFORMAÇÃO; } \\
\text { CONHECIMENTO }\end{array}$ & & INFORMAÇÃO \\
\hline $\begin{array}{l}\text { Cortez, P. } \\
\text { L. }\end{array}$ & $\begin{array}{l}\text { Revistas cientificas } \\
\text { eletrônicas on-line e } \\
\text { dinâmica da publicação, } \\
\text { divulgação e } \\
\text { comunicação científica: } \\
\text { um quadro conceitual }\end{array}$ & $\begin{array}{l}\text { PERIÓDICOS ELETRÔNICOS; } \\
\text { PERIÓDICOS CIENTÍFICOS; } \\
\text { INTERAÇÃO HOMEM-MÁQUINA; } \\
\text { INTERNET }\end{array}$ & $\begin{array}{l}\text { PERIÓDICOS } \\
\text { CIENTÍFICOS; } \\
\text { PESQUISA; } \\
\text { RELATORIOS }\end{array}$ & $\begin{array}{l}\text { PERIÓDICOS } \\
\text { CIENTÍFICOS; } \\
\text { PERIÓDICOS } \\
\text { ELETRÔNICOS; } \\
\text { PERIÓDICOS ON-LINE; } \\
\text { COMUNICAÇÃO } \\
\text { CIENTÍFICA }\end{array}$ \\
\hline $\begin{array}{l}\text { Derqui, P. } \\
\text { M.s }\end{array}$ & $\begin{array}{l}\text { Fundamentos dos } \\
\text { conceitos de informação } \\
\text { e conhecimento em } \\
\text { ciência da informação } \\
\text { através de uma } \\
\text { abordagem dos } \\
\text { paradigmas ... }\end{array}$ & $\begin{array}{l}\text { INFORMAÇÃO; CIÊNCIA DA } \\
\text { INFORMAÇÃO; } \\
\text { CONHECIMENTO }\end{array}$ & & $\begin{array}{l}\text { INFORMAÇÃO; } \\
\text { CONHECIMENTO; } \\
\text { AUTOPOIESE }\end{array}$ \\
\hline Dias, G. A. & $\begin{array}{l}\text { Periódicos científicos } \\
\text { eletrônicos brasileiros na } \\
\text { área de ciência da } \\
\text { informação } \$ \text { \$b analise } \\
\text { das dinâmicas de acesso } \\
\text { e uso }\end{array}$ & $\begin{array}{l}\text { PERIÓDICOS CIENTÍFICOS; } \\
\text { PERIÓDICOS ELETRÔNICOS; } \\
\text { CIÊNCIA DA INFORMAÇÃO }\end{array}$ & $\begin{array}{l}\text { PERIÓDICOS; } \\
\text { PERIÓDICOS } \\
\text { CIENTÍFICOS; } \\
\text { ARQUIVOS; } \\
\text { PESQUISA }\end{array}$ & $\begin{array}{l}\text { PERIÓDICOS } \\
\text { CIENTÍFICOS; } \\
\text { COMUNICAÇÃ̃O } \\
\text { CIENTÍFICA; } \\
\text { PERIÓDICOS } \\
\text { ELETRÔNICOS } \\
\end{array}$ \\
\hline Elias, I. B. & $\begin{array}{l}\text { Conservação e restauro } \\
\text { de obras de arte em } \\
\text { suporte de papel }\end{array}$ & $\begin{array}{l}\text { PATRIMÔNIO CULTURAL } \\
\text { (RESTAURAÇÃO) }\end{array}$ & & $\begin{array}{l}\text { CONSERVAÇÃO } \\
\text { PREVENTIVA; } \\
\text { RESTAURAÇÃ̃O DE } \\
\text { COLEÇÕES; PAPEL; }\end{array}$ \\
\hline Ferneda, E. & $\begin{array}{l}\text { Recuperação de } \\
\text { informação: análise sobre } \\
\text { a contribuição da ciência } \\
\text { da computação para a } \\
\text { ciência da informação }\end{array}$ & $\begin{array}{l}\text { CIÊNCIA DA COMPUTAÇÃO; } \\
\text { CIÊNCIA DA INFORMAÇÃO; } \\
\text { RECUPERAÇÃO DA } \\
\text { INFORMAÇÃO; INFORMAÇÃO }\end{array}$ & PESQUISA; & $\begin{array}{l}\text { CIÊNCIA DA } \\
\text { INFORMAÇÃO; } \\
\text { CIÊNCIA DA } \\
\text { COMPUTAÇÃO; } \\
\text { RECUPERAČ̃̃O DA } \\
\text { INFORMAÇÂO; }\end{array}$ \\
\hline $\begin{array}{l}\text { Ferreira, } \\
\text { D.T. }\end{array}$ & $\begin{array}{l}\text { O profissional da } \\
\text { informação e a gestão da } \\
\text { qualidade em serviços de } \\
\text { informação }\end{array}$ & $\begin{array}{l}\text { SERVIÇOS DE INFORMAÇÃO; } \\
\text { BIBLIOTECONOMIA; } \\
\text { CONTROLE DA QUALIDADE; } \\
\text { PROFISSIONAIS DA } \\
\text { INFORMAÇÃO; } \\
\text { BIBLIOTECÁRIOS }\end{array}$ & PESQUISA & $\begin{array}{l}\text { PROFISSIONAL DA } \\
\text { INFORMAÇÃO; } \\
\text { QUALIDADE; } \\
\text { CAPACITAÇẪO }\end{array}$ \\
\hline $\begin{array}{l}\text { Ferreira, } \\
\text { S.M.S.P }\end{array}$ & $\begin{array}{l}\text { Federação de bibliotecas } \\
\text { digitais em ciências da } \\
\text { comunicação }\end{array}$ & $\begin{array}{l}\text { BIBLIOTECA DIGITAL; } \\
\text { SERVIÇOS DE INFORMAÇÃO; } \\
\text { COMUNICAÇÃO CIENTÍFICA }\end{array}$ & $\begin{array}{l}\text { BIBLIOTECAS; } \\
\text { PERIÓDICOS } \\
\text { CIENTÍFICOS }\end{array}$ & $\begin{array}{l}\text { PERIÓDICOS } \\
\text { CIENTÍFICOS; } \\
\text { BIBLIOTECA DIGITAL }\end{array}$ \\
\hline Gozzi, R.M. & Oficina de informação & $\begin{array}{l}\text { BIBLIOTECAS; EDUCAÇÃO; } \\
\text { ENSINO INFANTIL; } \\
\text { EDUCOMUNICAÇÃOO }\end{array}$ & PESQUISA & $\begin{array}{l}\text { INFORMAÇÃO; } \\
\text { EDUCAÇÃO INFANTIL }\end{array}$ \\
\hline $\begin{array}{l}\text { Guizzardi } \\
\text { Filho, } \mathrm{O} \text {. }\end{array}$ & $\begin{array}{l}\text { A produção de } \\
\text { estatísticas com base em } \\
\text { registros administrativos }\end{array}$ & $\begin{array}{l}\text { INFORMAÇÃO; ESTATÍSTICA; } \\
\text { CONHECIMENTO }\end{array}$ & & INFORMAÇÃO \\
\hline $\begin{array}{l}\text { Hommerdin } \\
\text { g, N. M. dos } \\
\text { S. }\end{array}$ & $\begin{array}{l}\text { Em busca da avaliação de } \\
\text { bibliotecas digitais: } \\
\text { caminhos e descaminhos }\end{array}$ & $\begin{array}{l}\text { BIBLIOTECA DIGITAL; } \\
\text { AVALIAÇÃO DE COLEÇÕES; } \\
\text { AVALIAÇÃO DE SERVIÇOS; } \\
\text { AVALIAÇÃO DE USO DE } \\
\text { COLEÇÕES }\end{array}$ & $\begin{array}{l}\text { BIBLIOTECAS; } \\
\text { PESQUISA }\end{array}$ & BIBLIOTECA DIGITAL \\
\hline $\begin{array}{l}\text { Houssami, } \\
\text { H.S.I }\end{array}$ & $\begin{array}{l}\text { Cursos de pós-graduação } \\
\text { lato-sensu a distância }\end{array}$ & $\begin{array}{l}\text { EDUCAÇÃO A DISTÂNCIA - } \\
\text { BRASIL; FONTES DE } \\
\text { INFORMAÇÃO; PÓS- } \\
\text { GRADUAÇÃO - BRASIL }\end{array}$ & PESQUISA & $\begin{array}{l}\text { RECURSOS } \\
\text { INFORMACIONAIS; } \\
\text { INTERNET }\end{array}$ \\
\hline
\end{tabular}



automática

\begin{tabular}{|c|c|c|c|c|}
\hline AUTOR & TÍTULO & $\begin{array}{c}\text { INDEXAÇÃO MANUAL } \\
\text { NO DEDALUS }\end{array}$ & $\begin{array}{l}\text { INDEXAÇÃO } \\
\text { AUTOMÁTICA } \\
\text { (SISA) }\end{array}$ & $\begin{array}{l}\text { INDEXAÇÃO } \\
\text { SEMI- } \\
\text { AUTOMÁTICA }\end{array}$ \\
\hline $\begin{array}{l}\text { Igami, M. } \\
\text { P. Z. }\end{array}$ & $\begin{array}{l}\text { A avaliação de } \\
\text { desempenho na gestão } \\
\text { das bibliotecas } \\
\text { especializadas nos } \\
\text { institutos públicos de } \\
\text { pesquisa }\end{array}$ & $\begin{array}{l}\text { BIBLIOTECAS } \\
\text { ESPECIALIZADAS; } \\
\text { ADMINISTRAÇÃO DE } \\
\text { BIBLIOTECA; AVALIAÇÃO DE } \\
\text { SERVIÇOS }\end{array}$ & $\begin{array}{l}\text { BIBLIOTECAS; } \\
\text { BIBLIOTECAS } \\
\text { ESPECIALIZADAS; } \\
\text { PESQUISA; } \\
\text { INSTITUTOS DE } \\
\text { PESQUISA }\end{array}$ & $\begin{array}{l}\text { BIBLIOTECAS } \\
\text { ESPECIALIZADAS } \\
\text { ADMINISTRAÇÃO DE } \\
\text { BIBLIOTECA; } \\
\text { AVALIACCÃO DE } \\
\text { DESEMPENHO }\end{array}$ \\
\hline Imoto, I. & $\begin{array}{l}\text { Ação cultural na } 3^{a} \text { idade } \\
\text { qualidade de vida }\end{array}$ & IDOSOS, QUALIDADE DE VIDA & & AÇÃO CULTURAL \\
\hline $\begin{array}{l}\text { Jacomini, } \\
\text { D.D. }\end{array}$ & $\begin{array}{l}\text { A biblioteca universitária } \\
\text { e a educação a distância }\end{array}$ & $\begin{array}{l}\text { BIBLIOTECA UNIVERSITÁRIA; } \\
\text { SERVIÇOS DE INFORMAÇÃO; } \\
\text { EDUCAÇÃO A DISTÂNCIA }\end{array}$ & & $\begin{array}{l}\text { SERVIÇOS DE } \\
\text { INFORMAÇÃO; } \\
\text { EDUCAÇÃO A } \\
\text { DISTÂNCIA }\end{array}$ \\
\hline $\begin{array}{l}\text { Jannuzzi, C. } \\
\text { A.S. C. }\end{array}$ & $\begin{array}{l}\text { Gestão da informação } \\
\text { nas empresas }\end{array}$ & $\begin{array}{l}\text { CIÊNCIA DA INFORMAÇÃO; } \\
\text { GESTÃO DA INFORMAÇÃO }\end{array}$ & & $\begin{array}{l}\text { GESTÃO DA } \\
\text { INFORMAÇÃO }\end{array}$ \\
\hline Kessel, Z. & $\begin{array}{l}\text { A construção da memória } \\
\text { na Escola }\end{array}$ & $\begin{array}{l}\text { MEMÓRIA; HISTÓRIA } \\
\text { (EDUCAÇÃ̃O) }\end{array}$ & PESQUISA & $\begin{array}{l}\text { MEMÓRIA; AÇÃO } \\
\text { CULTURAL }\end{array}$ \\
\hline Kobashi, $\mathrm{H}$. & $\begin{array}{l}\text { Gestão do conhecimento } \\
\text { em empresa de } \\
\text { engenharia consultiva }\end{array}$ & $\begin{array}{l}\text { EMPRESAS (ORGANIZAÇÃO); } \\
\text { EMPRESAS (INFRA- } \\
\text { ESTRUTURA) }\end{array}$ & $\begin{array}{l}\text { ESTUDO DE CASO; } \\
\text { PESQUISA }\end{array}$ & $\begin{array}{l}\text { GESTÃO DO } \\
\text { CONHECIMENTO }\end{array}$ \\
\hline $\begin{array}{l}\text { Lara Filho, } \\
\text { D. de }\end{array}$ & $\begin{array}{l}\text { Museu: de espelho do } \\
\text { mundo a espaço } \\
\text { relacional }\end{array}$ & $\begin{array}{l}\text { MUSEUS; DOCUMENTAÇÃO } \\
\text { MUSEOLÓGICA }\end{array}$ & LIVROS; MUSEUS & MUSEUS \\
\hline Lima, J. A. & $\begin{array}{l}\text { Comunidades carentes, } \\
\text { lugares da não- } \\
\text { informação }\end{array}$ & $\begin{array}{l}\text { INFORMAÇÃO (ASPECTOS } \\
\text { SOCIAIS) - SÃO CRISTOVÃO } \\
\text { (SE); COMUNIDADES - SÃO } \\
\text { CRISTOVÃO (SE) }\end{array}$ & PESQUISA & $\begin{array}{l}\text { COMUNIDADES } \\
\text { CARENTES; } \\
\text { NECESSIDÁDES DE } \\
\text { INFORMAÇÃO }\end{array}$ \\
\hline $\begin{array}{l}\text { Lima, V. M. } \\
\text { A. da }\end{array}$ & $\begin{array}{l}\text { Da classificação do } \\
\text { conhecimento científico } \\
\text { aos sistemas de } \\
\text { recuperação de } \\
\text { informação: enunciação } \\
\text { de codificação e } \\
\text { enunciação da } \\
\text { informação documentaria }\end{array}$ & $\begin{array}{l}\text { LINGUAGENS } \\
\text { DOCUMENTÁRIAS; ANÁLISE } \\
\text { DOCUMENTÁRIA; } \\
\text { TERMINOLOGIA }\end{array}$ & $\begin{array}{l}\text { DOCUMENTOS; } \\
\text { PESQUISA }\end{array}$ & $\begin{array}{l}\text { INFORMAÇÃO } \\
\text { DOCUMENTÁRIA; } \\
\text { SISTEMAS DE } \\
\text { CLASSIFICAÇÃO; } \\
\text { LINGUAGENS } \\
\text { DOCUMENTÁRIAS; } \\
\text { SISTEMAS DE } \\
\text { RECUPERAÇÃO DE } \\
\text { INFORMAÇÃO }\end{array}$ \\
\hline $\begin{array}{l}\text { Manini, M. } \\
\text { P. }\end{array}$ & $\begin{array}{l}\text { Análise documentária de } \\
\text { fotografias }\end{array}$ & $\begin{array}{l}\text { FOTOGRAFIA; } \\
\text { DOCUMENTAÇÃO } \\
\text { FOTOGRÁFICA }\end{array}$ & $\begin{array}{l}\text { ANÁLISE } \\
\text { DOCUMENTÁRIA }\end{array}$ & $\begin{array}{l}\text { ANÁLISE } \\
\text { DOCUMENTÁRIA; } \\
\text { DOCUMENTAÇÃO } \\
\text { FOTOGRÁFICA ; } \\
\text { FOTOGRAFIA }\end{array}$ \\
\hline $\begin{array}{l}\text { Matos, } \\
\text { A.L.H. }\end{array}$ & Documentação musical & $\begin{array}{l}\text { DOCUMENTAÇÃO MUSICAL; } \\
\text { REPRESENTAÇÃO TEMÁTICA; } \\
\text { PARTITURAS }\end{array}$ & $\begin{array}{l}\text { PARTITURAS; } \\
\text { BIBLIOTECONOMIA; } \\
\text { BASES DE DADOS; } \\
\text { DOCUMENTOS }\end{array}$ & $\begin{array}{l}\text { PARTITURAS; } \\
\text { DOCUMENTAÇÃO } \\
\text { MUSICAL; } \\
\text { REPRESENTAÇÃO } \\
\text { TEMÁTICA } \\
\end{array}$ \\
\hline $\begin{array}{l}\text { Mattos, J. } \\
\text { F. de O. }\end{array}$ & $\begin{array}{l}\text { A representação por } \\
\text { palavras do conteúdo de } \\
\text { imagens em movimento } \\
\text { numa perspectiva } \\
\text { documentária }\end{array}$ & $\begin{array}{l}\text { FILMES; CIÊNCIA DA } \\
\text { INFORMAÇÃO; MULTIMEIOS }\end{array}$ & $\begin{array}{l}\text { ARQUIVOS; ANÁLISE } \\
\text { DE CONTEÚDO; } \\
\text { DOCUMENTOS; } \\
\text { FILMES }\end{array}$ & $\begin{array}{l}\text { ARQUIVOS; ANALISE } \\
\text { DE CONTEÚDO; } \\
\text { FILMES }\end{array}$ \\
\hline $\begin{array}{l}\text { Mugnaini, } \\
\text { R. }\end{array}$ & $\begin{array}{l}\text { Caminhos para a } \\
\text { adequação da avaliação } \\
\text { da produção científica } \\
\text { brasileira }\end{array}$ & $\begin{array}{l}\text { BIBLIOMETRIA; PESQUISA } \\
\text { CIENTÍFICA (AVALIAÇÃO) - } \\
\text { BRASIL }\end{array}$ & $\begin{array}{l}\text { PESQUISA; } \\
\text { PERIÓDICOS; } \\
\text { PERIÓDICOS } \\
\text { CIENTÍFICOS; }\end{array}$ & $\begin{array}{l}\text { PERIÓDICOS } \\
\text { CIENTÍFICOS; } \\
\text { BIBLIOMETRIA; } \\
\text { PRODUÇÃO } \\
\text { CIENTÍFICA } \\
\end{array}$ \\
\hline $\begin{array}{l}\text { Mutarelli, L. } \\
\text { de S.R. }\end{array}$ & $\begin{array}{l}\text { Os quadrinhos autorais } \\
\text { como meio de cultura e } \\
\text { informação }\end{array}$ & $\begin{array}{l}\text { HISTÓRIA EM QUADRINHOS } \\
\text { (EDUCAÇÃO); HISTÓRIA EM } \\
\text { QUADRINHOS - BRASIL }\end{array}$ & ESTUDO DE CASO & $\begin{array}{l}\text { LEITURA; REVISTAS } \\
\text { EM QUADRINHOS; } \\
\text { HISTÓRIA EM } \\
\text { QUADRINHOS }\end{array}$ \\
\hline
\end{tabular}



automática

\begin{tabular}{|c|c|c|c|c|}
\hline AUTOR & TÍTULO & $\begin{array}{c}\text { INDEXAÇÃO MANUAL } \\
\text { NO DEDALUS }\end{array}$ & $\begin{array}{c}\text { INDEXAÇÃO } \\
\text { AUTOMÁTICA } \\
\text { (SISA) }\end{array}$ & $\begin{array}{c}\text { INDEXAÇÃO } \\
\text { SEMI- } \\
\text { AUTOMÁTICA }\end{array}$ \\
\hline $\begin{array}{l}\text { Oliveira, É. } \\
\text { B.P.M. }\end{array}$ & $\begin{array}{l}\text { Uso de periódicos } \\
\text { científicos eletrônicos por } \\
\text { docentes e pós- } \\
\text { graduandos do Instituto } \\
\text { de Geociências da USP }\end{array}$ & $\begin{array}{l}\text { PERIÓDICOS ELETRÔNICOS; } \\
\text { PERIÓDICOS CIENTÍFICOS; } \\
\text { AVALIAĈ̃̃O DE USO DE } \\
\text { COLEÇÕES }\end{array}$ & $\begin{array}{l}\text { PERIÓDICOS; } \\
\text { PERIÓDICOS } \\
\text { CIENTÍFICOS; } \\
\text { PESQUISA; } \\
\text { PERIÓDICOS } \\
\text { ELETRÔNICOS }\end{array}$ & $\begin{array}{l}\text { PERIÓDICOS } \\
\text { CIENTÍFICOS; } \\
\text { PERIÓDICOS } \\
\text { ELETRÔNICOS; } \\
\text { COMUNICAÇÃO } \\
\text { CIENTÍFICA }\end{array}$ \\
\hline $\begin{array}{l}\text { Oliveira, L. } \\
\text { M.B.de }\end{array}$ & Corpos indisciplinados & $\begin{array}{l}\text { CULTURA - SÉCULO 20; } \\
\text { DESOBEDIÊNCIA CIVIL }\end{array}$ & & AÇÃO CULTURAL; \\
\hline $\begin{array}{l}\text { Ortega, } \\
\text { C.D. }\end{array}$ & $\begin{array}{l}\text { Informática } \\
\text { documentária; estado da } \\
\text { arte }\end{array}$ & $\begin{array}{l}\text { BIBLIOTECONOMIA; CIÊNCIA } \\
\text { DA INFORMAÇÃO; } \\
\text { RECUPERAÇÃO DA } \\
\text { INFORMAÇÃ̃O }\end{array}$ & $\begin{array}{l}\text { BIBLIOTECONOMIA; } \\
\text { BIBLIOTECAS; } \\
\text { PESQUISA }\end{array}$ & $\begin{array}{l}\text { BIBLIOTECONOMIA; } \\
\text { INFORMÁTICCA } \\
\text { DOCUMENTÁRIA; } \\
\text { CIÊNCIA DA } \\
\text { INFORMAÇÃO }\end{array}$ \\
\hline $\begin{array}{l}\text { Paula, T. C. } \\
\text { T.de }\end{array}$ & Tecidos no Brasil & $\begin{array}{l}\text { TECIDOS (HISTÓRIA; } \\
\text { CONSERVAÇÃO) - Século } \\
\text { Dezenove - BRASIL }\end{array}$ & & TECIDOS; MUSEUS \\
\hline $\begin{array}{l}\text { Penuela, } \\
\text { P.M. }\end{array}$ & $\begin{array}{l}\text { Mediação e ferramentas } \\
\text { pedagógicas no processo } \\
\text { de aprendizagem }\end{array}$ & $\begin{array}{l}\text { COMUNICAÇÁO; EDUCAÇÃO; } \\
\text { LIVROS DIDÁTICOS; } \\
\text { SOFTWARES; WEB SITES } \\
\text { (EDUCAÇÃO) }\end{array}$ & & $\begin{array}{l}\text { APRENDIZAGEM; } \\
\text { LIVROS DIDÁTICOS ; } \\
\text { MEDIAÇÃO }\end{array}$ \\
\hline $\begin{array}{l}\text { Pieruccini, } \\
\text { I. }\end{array}$ & $\begin{array}{l}\text { A ordem informacional } \\
\text { dialógica: estudo sobre a } \\
\text { busca de informação em } \\
\text { educação }\end{array}$ & $\begin{array}{l}\text { BIBLIOTECA ESCOLAR; } \\
\text { EDUCAÇÃO; USUÁRIOS DE } \\
\text { BIBLIOTECA; RECUPERAÇÃO } \\
\text { DA INFORMAÇÃO }\end{array}$ & $\begin{array}{l}\text { BIBLIOTECA } \\
\text { ESCOLAR }\end{array}$ & $\begin{array}{l}\text { BIBLIOTECA } \\
\text { ESCOLAR; } \\
\text { INFORMAÇÃO }\end{array}$ \\
\hline Pinto, L.P. & $\begin{array}{l}\text { A representação } \\
\text { documentária e o } \\
\text { paradigma social }\end{array}$ & $\begin{array}{l}\text { LINGUAGENS } \\
\text { DOCUMENTÁRIAS; BÍBLIA }\end{array}$ & & $\begin{array}{l}\text { ANÁLISE } \\
\text { DOCUMENTÁRIA; } \\
\text { RECUPERAČÃO DA } \\
\text { INFORMAĈ̃O }\end{array}$ \\
\hline $\begin{array}{l}\text { Reis, } \\
\text { G.A.dos }\end{array}$ & $\begin{array}{l}\text { Centrando a arquitetura } \\
\text { de informação no usuário }\end{array}$ & $\begin{array}{l}\text { ARQUITETURA DE } \\
\text { INFORMAÇÃO; WEB SITES; } \\
\text { INTERAÇÃO USUÁRIO- } \\
\text { COMPUTADOR }\end{array}$ & $\begin{array}{l}\text { PESQUISA; } \\
\text { PESQUISA } \\
\text { QUANTITATIVA; } \\
\text { PESQUISA } \\
\text { QUALITATIVA } \\
\end{array}$ & $\begin{array}{l}\text { ARQUITETURA DA } \\
\text { INFORMAÇÃO; } \\
\text { USUÁRIO }\end{array}$ \\
\hline $\begin{array}{l}\text { Rosetto, } \\
\text { Marcia }\end{array}$ & $\begin{array}{l}\text { Metadados e formatos de } \\
\text { metadados em sistemas } \\
\text { de informação }\end{array}$ & $\begin{array}{l}\text { RECUPERAÇÃO DA } \\
\text { INFORMAÇÃO }\end{array}$ & $\begin{array}{l}\text { METADADOS; } \\
\text { DOCUMENTOS; } \\
\text { PESQUISA }\end{array}$ & $\begin{array}{l}\text { METADADOS; } \\
\text { SISTEMAS DE } \\
\text { INFORMAÇÃO; } \\
\text { FORMATOS DE } \\
\text { CATALOGAÇÃO }\end{array}$ \\
\hline $\begin{array}{l}\text { Sampaio, } \\
\text { M.I. }\end{array}$ & $\begin{array}{l}\text { Motivação no trabalho } \\
\text { cooperativo }\end{array}$ & $\begin{array}{l}\text { BIBLIOTECÁRIOS - BRASIL; } \\
\text { BIBLIOTECAS - BRASIL; } \\
\text { MOTIVAÇÃO; BASES DE } \\
\text { DADOS }\end{array}$ & $\begin{array}{l}\text { BIBLIOTECAS; } \\
\text { BIBLIOTECA } \\
\text { VIRTUAL; COLETA DE } \\
\text { DADOS; PESQUISA }\end{array}$ & $\begin{array}{l}\text { BIBLIOTECA VIRTUAL; } \\
\text { MOTIVAÇÃO }\end{array}$ \\
\hline $\begin{array}{l}\text { Santos, C. } \\
\text { A.C.M. dos }\end{array}$ & $\begin{array}{l}\text { Linguagens } \\
\text { documentárias e } \\
\text { codificação da informação }\end{array}$ & $\begin{array}{l}\text { LINGUAGENS } \\
\text { DOCUMENTÁRIAS; } \\
\text { VOCABULÁRIO (ESTUDO); } \\
\text { SISTEMAS DE INFORMAÇÃ́O }\end{array}$ & $\begin{array}{l}\text { LINGUAGENS } \\
\text { DOCUMENTÁRIAS; } \\
\text { BASES DE DADOS; } \\
\text { BIBLIOTECA VIRTUAL }\end{array}$ & $\begin{array}{l}\text { LINGUAGENS } \\
\text { DOCUMENTÁRIAS; } \\
\text { BASES DE DADOS; } \\
\text { BIBLIOTECA VIRTUAL }\end{array}$ \\
\hline $\begin{array}{l}\text { Santos, P. } \\
\text { De M.L. dos }\end{array}$ & $\begin{array}{l}\text { O ponto de inflexão Otlet } \\
\text { : uma visão sobre as } \\
\text { origens da documentação } \\
\text { e o processo de } \\
\text { construção do princípio } \\
\text { monográfico }\end{array}$ & DOCUMENTAÇÃO & PESQUISA & $\begin{array}{l}\text { PRINCÍPIO } \\
\text { MONOGRÁFICO; } \\
\text { CLASSIFICAÇÃO } \\
\text { DECIMAL UNIVERSAL; } \\
\text { DOCUMENTAÇÃO }\end{array}$ \\
\hline $\begin{array}{l}\text { Santos, V.e } \\
\text { de M. }\end{array}$ & $\begin{array}{l}\text { Mediação documentária } \\
\text { em ambientes educativos } \\
\text { do terceiro setor }\end{array}$ & $\begin{array}{l}\text { RECUPERAČ̃̃O DA } \\
\text { INFORMAÇÃO; LINGUAGENS } \\
\text { DOCUMENTÁRIAS; SERVIÇOS } \\
\text { DE INFORMAÇÃO; TERCEIRO } \\
\text { SETOR; BIBLIOTECA ESCOLAR } \\
\text { (ORGANIZAÇÃO) }\end{array}$ & $\begin{array}{l}\text { LINGUAGENS } \\
\text { DOCUMENTÁRIAS; } \\
\text { PESQUISA }\end{array}$ & $\begin{array}{l}\text { LINGUAGENS } \\
\text { DOCUMENTÁRIAS; } \\
\text { MEDIAÇÃO }\end{array}$ \\
\hline
\end{tabular}



automática

\begin{tabular}{|c|c|c|c|c|}
\hline AUTOR & TÍTULO & $\begin{array}{c}\text { INDEXAÇÃO MANUAL } \\
\text { NO DEDALUS }\end{array}$ & $\begin{array}{c}\text { INDEXAÇÃO } \\
\text { AUTOMÁTICA } \\
\text { (SISA) }\end{array}$ & $\begin{array}{c}\text { INDEXAÇÃO } \\
\text { SEMI- } \\
\text { AUTOMÁTICA }\end{array}$ \\
\hline Schultze, S. & $\begin{array}{l}\text { Características de } \\
\text { periódicos científicos } \\
\text { produzidos por editoras } \\
\text { universitárias brasileiras }\end{array}$ & $\begin{array}{l}\text { EDITORAS UNIVERSITÁRIAS - } \\
\text { BRASIL; PERIÓDICOS } \\
\text { CIENTÍFICOS - BRASIL }\end{array}$ & $\begin{array}{l}\text { PERIÓDICOS; } \\
\text { PERIÓDICOS } \\
\text { CIENTÍFICOS; } \\
\text { LIVROS; PESQUISA }\end{array}$ & $\begin{array}{l}\text { PERIÓDICOS } \\
\text { CIENTÍFICOS }\end{array}$ \\
\hline So, D. R. & $\begin{array}{l}\text { A segmentação de } \\
\text { clientes em bibliotecas }\end{array}$ & $\begin{array}{l}\text { MARKETING DE BIBLIOTECA; } \\
\text { SEGMENTAÇÃO DE MERCADO }\end{array}$ & BIBLIOTECAS & $\begin{array}{l}\text { BIBLIOTECAS; } \\
\text { MARKETING DE } \\
\text { BIBLIOTECA }\end{array}$ \\
\hline $\begin{array}{l}\text { Tojal, A. P. } \\
\text { da F. }\end{array}$ & $\begin{array}{l}\text { Políticas públicas } \\
\text { culturais de inclusão de } \\
\text { públicos especiais em } \\
\text { museus }\end{array}$ & $\begin{array}{l}\text { MUSEUS PARA DEFICIENTES; } \\
\text { POLIITICA CULTURAL; } \\
\text { INCLUSÃO SOCIAL; MUSEUS }\end{array}$ & MUSEUS & $\begin{array}{l}\text { MUSEUS; INCLUSÃO } \\
\text { SOCIAL; POLÍTICAS } \\
\text { PÚBLICAS }\end{array}$ \\
\hline $\begin{array}{l}\text { Torres, N. } \\
\text { A. D. }\end{array}$ & $\begin{array}{l}\text { Motivação no trabalho e } \\
\text { clima organizacional: } \\
\text { estudo nas bibliotecas } \\
\text { universitárias brasileiras } \\
\text { e colombianas }\end{array}$ & $\begin{array}{l}\text { BIBLIOTECA UNIVERSITÁRIA - } \\
\text { BRASIL; COLÔMBIA; } \\
\text { ADMINISTRAÇÃO DE } \\
\text { RECURSOS HUMANOS; } \\
\text { MOTIVAÇÃO DO EMPREGADO }\end{array}$ & PESQUISA & $\begin{array}{l}\text { MOTIVAÇÃO; } \\
\text { BIBLIOTECA } \\
\text { UNIVERSITÁRIA; } \\
\text { BIBLIOTECÁRIOS }\end{array}$ \\
\hline $\begin{array}{l}\text { Valls, } \\
\text { Valéria } \\
\text { Martin }\end{array}$ & $\begin{array}{l}\text { Gestão da qualidade em } \\
\text { serviços de informação } \\
\text { no Brasil }\end{array}$ & $\begin{array}{l}\text { CIÊNCIA DA INFORMAÇÃO; } \\
\text { COMUNICAÇÃO }\end{array}$ & PESQUISA & $\begin{array}{l}\text { QUALIDADE; } \\
\text { SERVIÇOS DE } \\
\text { INFORMAÇÃO }\end{array}$ \\
\hline $\begin{array}{l}\text { Vogel, M. J. } \\
\text { M. }\end{array}$ & $\begin{array}{l}\text { A noção de estrutura } \\
\text { lingüística e de processo } \\
\text { de estruturação e sua } \\
\text { influência no conceito e } \\
\text { na elaboração de } \\
\text { linguagens } \\
\text { documentárias }\end{array}$ & $\begin{array}{l}\text { LINGUAGENS } \\
\text { DOCUMENTÁRIAS; } \\
\text { LINGÜÍSTICA }\end{array}$ & $\begin{array}{l}\text { LINGUAGENS } \\
\text { DOCUMENTARIAS; }\end{array}$ & $\begin{array}{l}\text { LINGUAGENS } \\
\text { DOCUMENTÁRIAS; } \\
\text { LINGUÍSTICA } \\
\text { DOCUMENTÁRIA; } \\
\text { TERMINOLOGIA }\end{array}$ \\
\hline $\begin{array}{l}\text { Weitzel, } \\
\text { S.da R. }\end{array}$ & $\begin{array}{l}\text { Os repositórios de e- } \\
\text { prints como nova forma } \\
\text { de organização da } \\
\text { produção científica }\end{array}$ & $\begin{array}{l}\text { PESQUISA CIENTÍFICA; } \\
\text { COMUNICAÇÕES; BIBLIOTECA } \\
\text { DIGITAL }\end{array}$ & $\begin{array}{l}\text { ARQUIVOS; } \\
\text { ARQUIVOS } \\
\text { ABERTOS; ESTUDO } \\
\text { DE CASO; PESQUISA }\end{array}$ & $\begin{array}{l}\text { ARQUIVOS ABERTOS; } \\
\text { INFORMAÇÃO } \\
\text { CIENTÍFICA; } \\
\text { PRODUÇÃO } \\
\text { CIENTÍFICA }\end{array}$ \\
\hline Wilder, G.S. & $\begin{array}{l}\text { As artes visuais do século } \\
\text { XX como visão de mundo } \\
\text { e exercício de } \\
\text { diversidade; Inclusão } \\
\text { cultural }\end{array}$ & $\begin{array}{l}\text { ÉTICA; CIDADANIA; ARTE } \\
\text { CONTEMPORÂNEA; MUSEUS } \\
\text { DE ARTE; IDENTIDADE } \\
\text { CULTURAL }\end{array}$ & $\begin{array}{l}\text { MUSEUS; MUSEUS } \\
\text { ARTE; PESQUISA }\end{array}$ & $\begin{array}{l}\text { MUSEUS; MUSEUS } \\
\text { ARTE; INCLUSÃO } \\
\text { SOCIAL }\end{array}$ \\
\hline Zen, A.M.D. & $\begin{array}{l}\text { A voz dos ausentes na } \\
\text { terra do nada }\end{array}$ & $\begin{array}{l}\text { DESENVOLVIMENTO } \\
\text { SUSTENTÁVEL; SÃO JOSÉ DOS } \\
\text { AUSENTES (RS) }\end{array}$ & PESQUISA & AÇÃO CULTURAL \\
\hline
\end{tabular}

